\title{
Wealth Inequality, Governance and Economic Growth in China
}

\author{
Tian Aw Yong \\ South China Normal University, China. \\ Email:Tianaw.yong@gmail.com
}

\begin{abstract}
Recently, there has been an increasing interest from policymakers, advocates and researchers on the extent to which the growth of the economy can impact income inequality. This research has been focused on the relationship between these variables. The author has recognized the need to focus on wealth as the income indicator, as well as the importance of studying wealth inequality (WI). This is more viable and important than researching income inequality, as this has been studied extensively, as has the impact that governance policies have on the growth of a country's economy. For the purpose of examining these variables, data from 30 selected Chinese provinces has been used. The panel dataset from 2000-2012 has been extracted from Credit Suisse. This study has predominantly investigated the impact of wealth inequality on economic growth (EG). The study has made use of the GMM estimation system in order to suggest that wealth inequality has a negative impact on the EG of China. Moreover, this empirical investigation has revealed the fact that the impact of wealth inequality on EG has been mitigated by an improved quality of governance.
\end{abstract}

Keywords: Wealth inequality; Economic growth; Governance; GMM growth estimator.

Citation | Tian Aw Yong (2020). Wealth Inequality, Governance and Economic Growth in China. Asian Journal of Economics and Empirical Research, 7(2): 235-241.

History:

Received: 7 July 2020

Revised: 10 August 2020

Accepted: 14: September 2020

Published: 29 September 2020

Licensed: This work is licensed under a Creative Common

Attribution 3.0 License (cc))

Publisher: Asian Online Journal Publishing Group
Funding: This study received no specific financial support

Competing Interests: The author declares that there are no conflicts of interests regarding the publication of this paper.

Transparency: The author confirms that the manuscript is an honest, accurate, and transparent account of the study was reported; that no vital eccurate, and the study have been onitted; and that any discrepancies from the study as planned have been explained.

Ethical: This study follows all ethical practices during writing.

\section{Contents}

1. Introduction

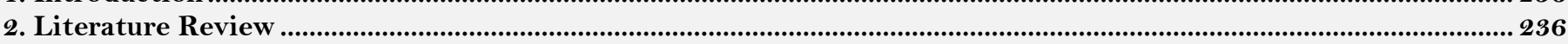

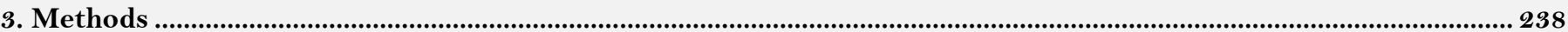

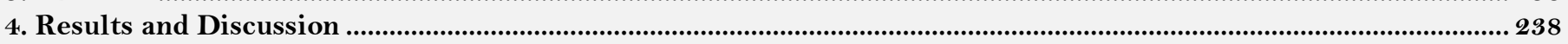

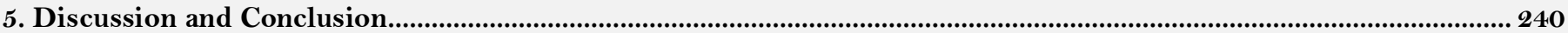

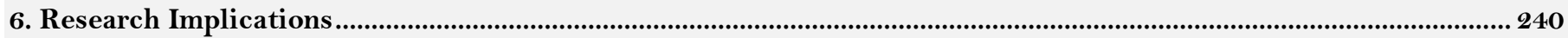

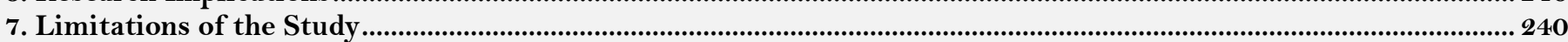

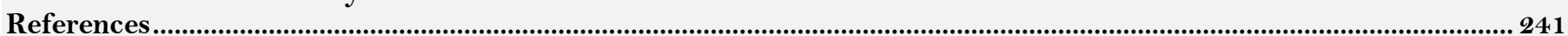




\section{Contribution of this paper to the literature}

This study contributes to existing literature by investigating the relationship between Wealth

Inequality, Governance and Economic Growth in 30 selected Chinese provinces.

\section{Introduction}

Generally, the rate of EG is inversely proportional to the rate of wealth inequality (WI). This helps to determine the potential causes and implications of the functional distribution of the wealth approach (Berg \& Ostry, 2017). The increase in WI is a result of several policies in China, including the long-term growth of the economy and long-lasting and high-speed efficiency (Zhao \& Tang, 2018). According to Riti, Song, Shu, and Kamah (2017), political pressure has increased due to WI, which has resulted in a reduction of growth and investment. Furthermore, socio-political instability is an issue derived from inequalities that have resulted in the slowing down of growth and capital accretion. The effects of WI on EG in China can be alleviated by improved governance and supremacy (Shi \& Sun, 2017).

Wealth equality (WE) and governance have been gaining significant attention from academic practitioners and scholars over the past few years (Wu \& Li, 2017), who have explored the fact that, even now, a wealth equality gap exits in the economic performance of a country (Piketty, Yang, \& Zucman, 2019). Li (2016) has recommended that, in order to address the governance and WE limitations, some important contextual factors that directly affect the overall EG of a nation need to be identified and evaluated in detail. As research on WE and governance are rare, studies on the EG of developing regions need to be conducted (Zhou \& Song, 2016), and the impact of human capital (HC) must also be tested (Wei, Wu, \& Zhang, 2019). Diao (2018) identified and evaluated the impact of technology and physical capital on the overall EG of the country. Furthermore, understanding wealth and governance from the perspective of economic development is significant. Therefore, this research explores the impact of WI and governance on the EG of China. Figure 1 shows the income inequality in China over the last 12 years.

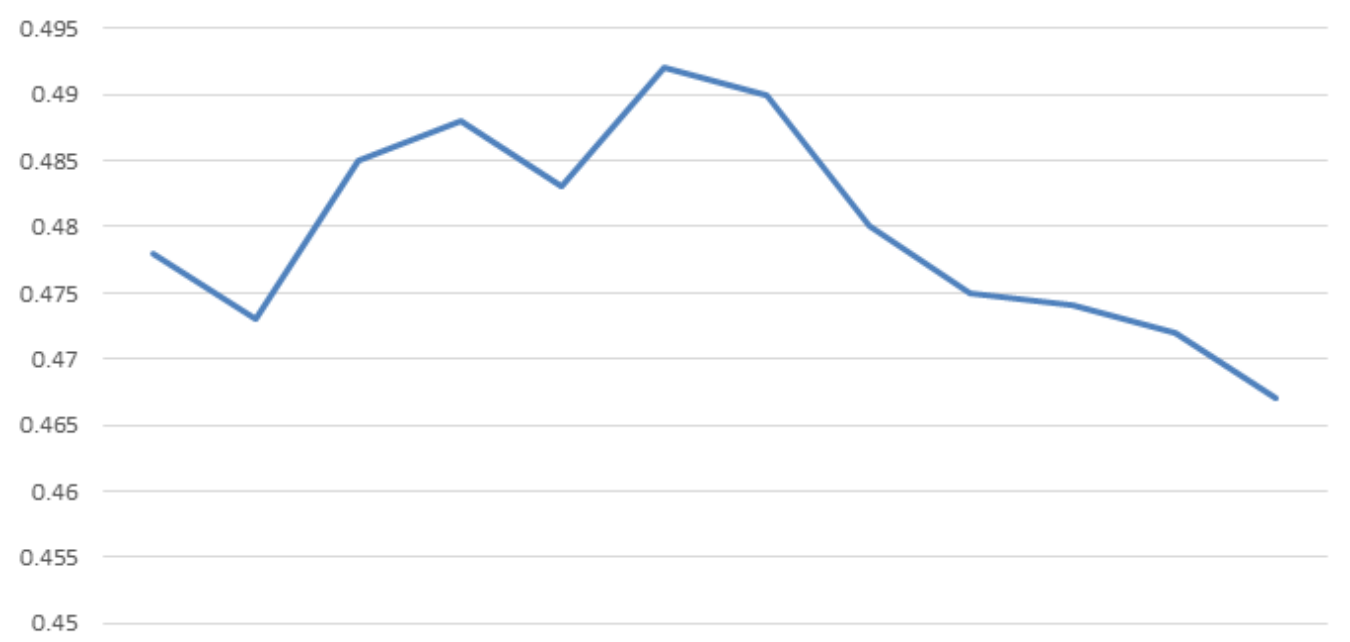

200820092010201120122013201420152016201720182019

Figure-1. Wealth inequality n China

Following the above discussion and justification statement, the initial and major objective of the current study is to analyze the impact of WI on the EG of China; the second purpose of the study is to investigate the relationship between governance and economic performance in China. The current paper also empirically investigates the impact of WI on the overall economic presentation of China in the current situation, predominantly using Credit Suisse's information and statistics. In summary, the particular interest of the following research are the connections between EG, wealth, and governance activities in China. Factual and observed findings point to negative connections between WI and EG; they recommend that the insignificant impact of WI on development may become significant in nations with enhanced governance activities.

China is one of the developing countries that has been facing issues related to WI (Guan, Wei, Lu, Dai, \& Su, 2018). The scope of this study covers the influence of WI on EG and governance of China, as the link between economic inequality and growth in China has become a topic of interest (Liu, 2018). This study provides useful implications for the Chinese government regarding the development of its economy. The particular significance of this study lies in its focus on the economic development of China and its use of the theory of economic inequality to study the relationship between WI, governance, and EG.

The research study is organized as follows: Sections two and three present the empirical and observed model and framework, data, methods, and techniques, respectively; Section four presents the estimations and calculations; robustness checks are presented in Section five; the results and discussion are presented in Section six; and the last section concludes the by presenting the findings and implications of the study.

\section{Literature Review}

There is a huge variation of economic inequalities (EI); and EI is most notably measured using the distribution of income (the amount of public money paid) and the distribution of wealth (the amount of money and wealth the public owns). The theory also states that, in addition to the EI between nations and regions, there are also significant types of EI between different groups of the public (Bapuji, Ertug, \& Shaw, 2020). According to this theory, significant types of EG measurements focus on wealth, income, and, sometimes, consumption. The theory also suggests that a greater level of inequality hinders the overall EG of the country, as land and HC inequality minimizes development and increases income inequality. Whereas globalization has minimized global inequality between countries, it has improved inequality within states and countries (Bapuji \& Chrispal, 2018). Furthermore, 
this theory suggests that a degree of inequality can have a significant and positive impact on EG in the short-term; however, some theories and models have found empirical proof of an insignificant correlation of about 0.4-0.7\% between long-term growth rates and sustained EI. According to this theory, EG is suppressed in economically unequal countries and societies after a phase of improved development and growth, owing to a reduction in the availability of investments for public capital (Ritter \& Solt, 2019). Furthermore, physical capital is becoming scarce, as fewer peoples have funds to invest in education and training. As a consequence, needs for $\mathrm{HC}$ are critical or impossible to meet, which leads to a reduction in EG (Ruck, Mistry, \& Flanagan, 2019). Consequently, the market needs to improve in order to better deal with risky unsecured loans, which further enhance the lender's risk exposure. Moreover, this theory also states that, when wealth distribution becomes concentrated in a small number of politicians, political power tends to become unstable. This affects the effectiveness of governance, which further affects the EG of the nation.

\subsection{Wealth Inequality and Economic Growth}

According to Islam and McGillivray (2019), the most notable methods to measure income distribution include the total amount of public money paid and the distribution of wealth, which is the amount of money and wealth the public owns. Furthermore, the theory also states that, in addition to EI between nations and regions, there are also significant types of EI between different groups of the public (Stiglitz, 2016). According to this theory, significant types of EG measurements focus on wealth, income, and sometimes consumption (Adrián Risso \& Sánchez Carrera, 2019). Akinci (2018) illustrates that the theory also suggests that a greater level of inequality hinders the overall EG of the country, with land and human capital (HC) inequality minimizing development more than income inequality. Although globalization has minimized global inequality between countries, it has also heightened inequalities between states and countries (Lorenzi, 2016). Furthermore, this theory also suggests that a degree of inequality can have a significant and positive impact on EG in the short-term; however, some theories and models have found empirical proof of an insignificant correlation of about 0.4-0.7\% between long-term growth rates and sustained EI (Chen, Lee, \& Tsai, 2019; Scheffer, Van Bavel, Van de Leemput, \& Van Nes, 2017). According to this theory, EG is suppressed in economically unequal countries and societies after a phase of improved development and growth, owing to a reduction in the availability of investments for public capital. Furthermore, as physical capital is scarce, fewer people have the funds to invest in education and training. As a consequence, needs for HC are critical or impossible to meet, which leads to a reduction in EG (Lee \& Son, 2016). Consequently, the market needs to improve in order to better deal with risky unsecured loans, which further enhance the lender's risk exposure. Moreover, this theory also states that, when wealth distribution becomes concentrated in a small number of politicians, political power tends to become unstable. This affects the effectiveness of governance, which further affects the EG of the nation. The above discussion leads to the development of the following hypothesis:

H1: There is a direct and significant relationship between WI and the EG of the country.

\subsection{Governance and Economic Development}

Research conducted by Ogidan, Adekola, Grace, and Oluwanishola (2017) briefly explored the fact that better governance leads to better economic development. Good governance results in a sustainable environment that helps to enhance economic development, as the use of innovative technology is related to good governance. Improved governance can help a country to overcome WI, which leads to an improvement in the credit sector so that its products can increase. If a country is well governed, the small issue of WI cannot harm the growth of its economy; in fact, it can help to provide high-quality products. It has been stated by Kyriacou (2016) that the negative effects of WI can be made positive by laudable and significant governance. Countries that face the problem of credit inequality should have a better and more advanced governance, so that EG can increase; this will change a developing country into a developed country (Scheve \& Stasavage, 2017). Most small organizations do not focus on governance; thus, they face the problem of reduced EG and credit inequality. Azam (2016) has described the fact that governance can be considered as the certain manner or order in which authority is implemented in terms of the administration of a country's social and economic resources with regard to its development. Governments are regularly replaced, monitored, and selected during the process of governance, depending on their capacity to implement strategies and policies and garner the respect of the residents in a country. Governance helps to govern social and economic interactions between institutions. As such, corruption can lead to the issue of WI and poverty, which could result in a reduction in the growth of a country's economy; however, this issue can be resolved with advanced governance. The variations within countries with regard to the distribution of wealth and EG can be investigated efficiently and reliably through sustainable governance. It has been proven by Franz (2017) that EG and WI are highly dependent on the governance of the country, i.e. EG is reduced by WI. However, this can be decreased through enhanced governance and the ability to restrict the unequal dissemination of wealth across several economies. The theory of economic inequality has stated that EG measurements focus on income, wealth, and consumption. Additionally, the greater level of inequality obstructs the overall EG of a country, along with land and $\mathrm{HC}$ inequality, by minimizing development more than credit inequality. Based on the above discussion, the present research poses the following hypothesis:

H2: There is a direct and positive connection between governance practices and the EG of a nation.

\subsection{Model Specification}

The author of this research has used an unbalanced panel growth regression model to analyze the empirical links between the variables of WI and growth (Johnson, de Dios, \& Martin, 2010). This model is presented as follows:

$$
\Delta \ln G D P_{i t}=\alpha_{i}+\beta_{1} \ln G D P_{i, t-1}+\beta_{2} W I N_{i t}+\lambda X_{i t}+\pi_{i}+\rho_{t}+\epsilon_{i t}
$$

In Equation 1, the $\Delta \ln G D P_{i t}$ represents the per capita GDP growth rate that is measured using the first difference of the natural logarithm of the value, $\ln G D P_{i, t-1}$, which is the natural logarithm that has been used to calculate the per capita real GDP that has been lagged at one period. The measurement of WI is shown by WIN it $_{\text {, }}$ 
which has been measured in the wealth share of the top ten percent; $X_{i t}$ represents the control variables that include the measurement of trade openness, the rate of inflation, institutional quality, the ratio of investment, school attainment, and population growth. The fixed effects that are unobserved are represented by $\pi_{i}$, and $\rho_{t}$ is used as the time dummy. Finally, the random error is indicated as $\epsilon_{i t}$.

\subsection{Data}

The variables specified in the model presented in Equation 1 have been constructed as follows:

- As previously mentioned, the real per capita GDP growth rate has been measured using the first difference of its natural logarithm. In the equation, $\alpha$ represents the income share of the capital of China, which has been set to 0.30 following guidelines by Gollin (2002).

- The measurement of WI has been taken as the wealth share made by the top ten percent of the population. The wealth share data has been acquired from a recent credit report (Suisse, 2013). The researcher has considered the top wealth share as a measurement of WI because:

- It is easy and simple to understand.

- It is not exposed to oversensitivity of the lower levels of wealth changes.

- Faster growth occurs in the top portions of the wealth share.

- The Gini coefficient supports this selection, and the top percentile is the most commonly used measure in research on WI (Suisse, 2013).

The researcher has made use of several control variables in this study, including:

- Gross fixed investment over GDP (ratio).

- Average number of years of schooling of those who are 25 years old and above.

- Sum of the exports and imports over the GDP (ratio).

- Population growth rate.

- Rate of inflation (measured as the consumer price index inflation).

- Institutional stability.

In addition, the researcher has taken into account a poverty ratio, which is the percentage of the population that lives below the threshold of $\$ 1.9$ per day, in order to estimate the impact of poverty on the WI growth rate. The dataset from 2000-2012 of 30 selected Chinese provinces have been extracted from Credit Suisse.

\section{Methods}

The researcher has used the GMM estimator to conduct the empirical estimation of Equation 1, which has been used to handle the issues of unobserved heterogeneity and endogeneity in the estimation data. This estimator performs better in the presence of these issues, compared to other simpler estimators (Baum, Schaffer, \& Stillman, 2003). This estimator is a preferred methodology for the calculation of growth models because it has the ability to exploit restrictions of stationarity. The dynamic panel model, thus, is as follows:

$$
y_{i t}-y_{i, t-1}=(\alpha-1) y_{i, t-1}+\hat{\beta} X_{i t}+\pi_{i}+\rho_{t}+\epsilon_{i t}
$$

In Equation 2, y represents real per capita GDP; $\mathrm{X}$ is the marker for the explanatory variables except for the value of $\mathrm{y}$ and $\pi$; and $\rho$ and $\varepsilon$ are the same as in Equation 1. The following equation represents this model after it has been re-parameterized:

$$
y_{i t}=\alpha y_{i, t-1}+\dot{\beta} X_{i t}+\pi_{i}+\rho_{t}+\epsilon_{i t}
$$

In Equation 3, there is a simultaneity problem because the lagged value of the dependent variable has been correlated with the fixed effects; therefore, the following first difference equation has been proposed (Arellano \& Bover, 1995):

$$
\Delta y_{i t}=\alpha \Delta y_{i, t-1}+\dot{\beta} \Delta X_{i t}+\Delta \epsilon_{i t}
$$

In Equation 4, $\Delta$ is used to show the first difference operator. For the purpose of handling the endogeneity in the regressors and the issues of potential correlations, an instrumental variable approach will be used in Equation 4.

The researcher has used the GMM estimator because the proposed relationship between WI and EG has a tendency to be impacted by issues such as endogeneity and reverse causality, and the endogenous variables have been instrumented in a suitable lag form so that they do not correlate to error terms. Even though the GMM model may not fully resolve these issues, it will provide a better result than an OLS regression model. The Hansen test has been used to consider the validity of the instruments, and the F-statistics have been calculated to show the joint significance of the estimated coefficients. Moreover, $\operatorname{AR}(1)$ and $\operatorname{AR}(2)$ tests have been performed to check he serial correlation in the error term. Finally, the GMM made an assumption that there is no correlation in the crosssectional error terms and, therefore, period dummies have been used (Roodman, 2009).

\section{Results and Discussion}

The regression results are provided in this section. The impact of WI and governance on the EG of China were initially calculated using a simple OLS regression and then by the GMM estimator, in order to analyze the effects of lagged parameters and ensure the robustness of the findings.

Table 1 presents the results of the OLS estimations for Equation 1 in China between 2000-2012. The analysis is proceeded with the estimations of the baseline regressions for the model defined in Equation 1. In Table 1, columns (1) and (4) present the regression results, which show that the growth of GDP per capita has regressed in terms of WI and the lagged parameter of GDP per capita. 


\begin{tabular}{|c|c|c|c|c|c|c|}
\hline Variables & $(1)$ & $(2)$ & $(3)$ & $(4)$ & $(5)$ & $(6)$ \\
\hline $\mathrm{WI}_{\text {it }}$ & $\begin{array}{c}-0.15^{*} * * \\
(-2.82)\end{array}$ & $\begin{array}{c}-0.17 * * \\
(-2.22)\end{array}$ & $\begin{array}{l}-0.19^{*} \\
(2.03)\end{array}$ & $\begin{array}{c}-0.19^{* *} * \\
(-2.43)\end{array}$ & $\begin{array}{l}-0.22^{*} \\
(-1.82)\end{array}$ & $\begin{array}{c}-0.23 \\
(-1.58)\end{array}$ \\
\hline $\begin{array}{l}\text { Ln (Real GDP Per } \\
\left.\text { Capita }_{\mathrm{i}, \mathrm{t}} 1\right) \\
\text { Investment Ratio it }\end{array}$ & $\begin{array}{l}-0.02^{*} \\
(-1.63)\end{array}$ & $\begin{array}{c}-0.07 * * * \\
(-3.38) \\
-0.43 * * * \\
(-3.87) \\
\end{array}$ & $\begin{array}{c}-0.08 * * * \\
(-2.75) \\
0.44 * * * \\
(4.24) \\
\end{array}$ & $\begin{array}{l}-0.03^{*} \\
(-1.88)\end{array}$ & $\begin{array}{c}-0.09 * * * \\
(-3.37) \\
-0.42 * * * \\
(-3.85) \\
\end{array}$ & $\begin{array}{c}-0.09 * * * \\
(-2.94) \\
-0.43 * * * \\
(4.17) \\
\end{array}$ \\
\hline School Attainment it & & $\begin{array}{c}0.02 \\
(0.67)\end{array}$ & $\begin{array}{c}0.02 \\
(0.53)\end{array}$ & & $\begin{array}{c}0.02 \\
(0.87)\end{array}$ & $\begin{array}{c}0.02 \\
(0.66)\end{array}$ \\
\hline Trade Openness it & & $\begin{array}{c}\text { O.03*** } \\
(4.29)\end{array}$ & $\begin{array}{c}0.04 * * * \\
(3.23)\end{array}$ & & $\begin{array}{c}0.05^{* * *} * \\
(4.08)\end{array}$ & $\begin{array}{c}0.04^{* * * *} \\
(2.85) \\
\end{array}$ \\
\hline $\begin{array}{c}\text { Population Growth }_{\text {ist }} \\
\text { Inflation }_{\text {ist }} \\
\text { Polity it }^{\text {Pol }}\end{array}$ & & $\begin{array}{c}-0.02 \\
(-1.07)\end{array}$ & $\begin{array}{l}-0.02 \\
(-1.12) \\
0.12 * * \\
(-2.54) \\
0.02 \\
\quad(1.07)\end{array}$ & & $\begin{array}{c}-0.02 \\
(-1.08)\end{array}$ & $\begin{array}{c}-0.02(-1.25)- \\
0.13^{* *} \\
-(2.52) \\
0.02 \\
(0.88)\end{array}$ \\
\hline -R-Squared & 0.23 & 0.37 & 0.38 & 0.23 & 0.33 & 0.37 \\
\hline
\end{tabular}

Note: $*, * *$ and $* * *$ depicts $0.10,0.05$ and 0.01 levels of significant respectively,

Table 2. Two-step GMM

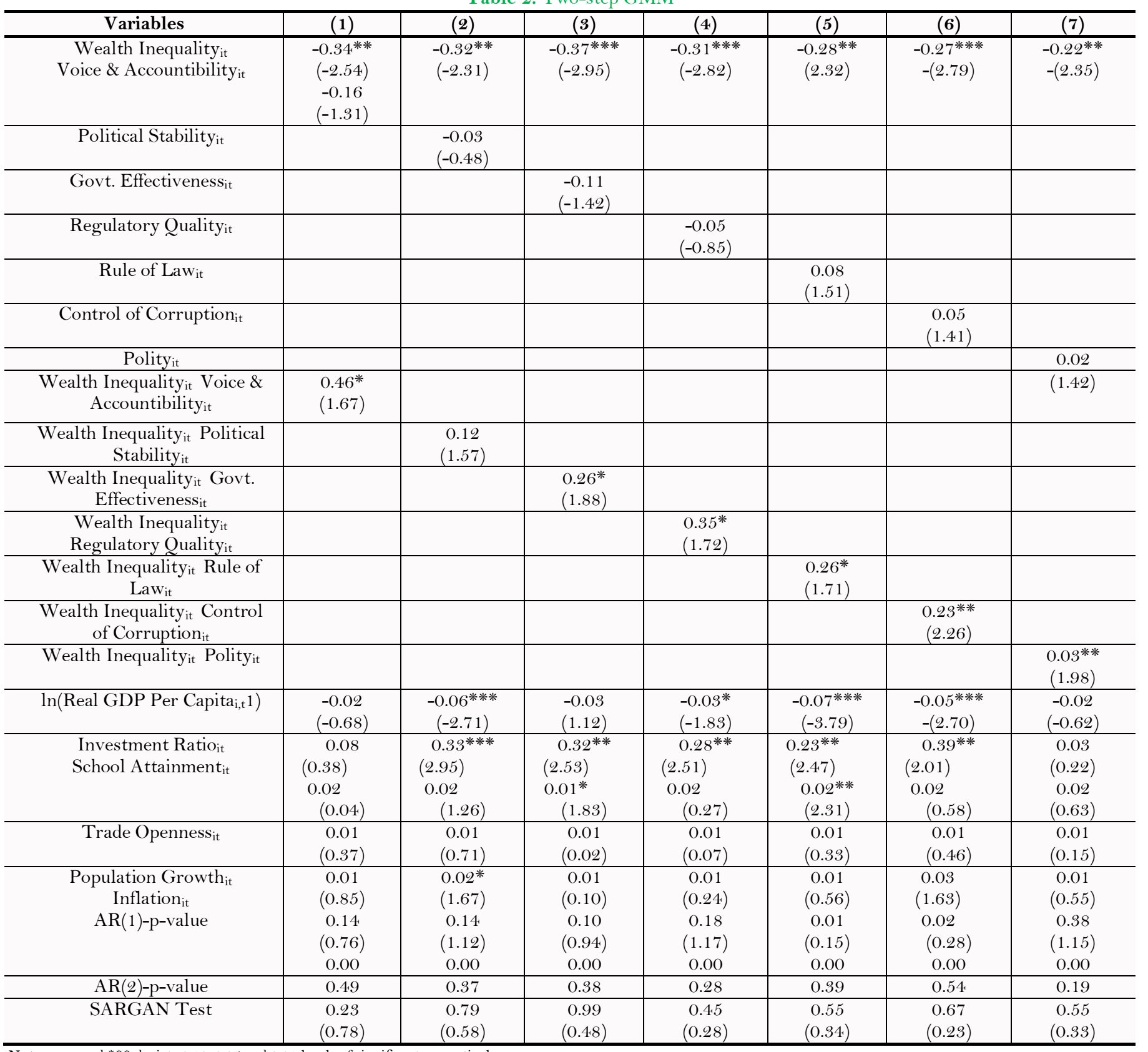

The estimated parameters of WI are 1.15 and 0.19 for the wealth share of the top one and ten percent of China's population. The estimated coefficients were found to be negative and statistically significant. This indicates that unequal wealth distribution considerably weakens the GDP per capita, i.e. the average income earned by each individual in an economy. These findings suggest that the region is characterized by an unequal distribution of wealth, as China has a detrimental and negative growth output. In the models displayed in columns (2) and (4), the control variables - investment, trade openness, population growth, and schooling-have been included in the regression estimation as well. The coefficients of WI have increased. However, they remain negative and are significant at the five percent level. In columns (3) and (6), the complete set of control variables, including inflation and policy formulation, have been added to the regression estimation procedure so that the complete effect of these factors on the growth output of China can be evaluated. The variable inflation serves as a proxy term for the 
stability of the macroeconomic policy, which is used as an evaluative indicator for the measurement of institutional quality. The coefficients of WI were found to have remained negative, which implying an inverse relationship. This suggests that an increase in GDP per capita reduces WI, and an increase in WI is detriment to GDP per capita and, ultimately, the growth of China. The coefficients were found to have a relatively weak significance. These findings suggest that the proportionate distribution of wealth, proper policy infrastructure, trade regulations, and education attainments will increase the EG of China, and a reasonable distribution of resources across the population will help the EG of the Chinese nation.

\subsection{System GMM Growth and Governance Effects}

Table 2 presents the results of the estimations of Equation 1 using the two-step GMM estimation, which is used for the evaluation of robustness. This includes AR1 and AR2 tests that evaluate the first and second order serial correlations. Moreover, the SARGAN test has been used to evaluate the model's over-estimation.

The tests and evaluations of the robustness are significant. The coefficients of WI were found to be negative and statistically significant, which suggests the same findings as in Table 1. However, the GMM estimations show that, in comparison to the OLS estimations in Table 1, the estimated coefficients for WI are considerably higher and are also more significant, which indicates the fact that estimations in the first computation was subject to some measurement biases that have been eradicated in the GMM estimation. On average, a unit increase in the inequality of wealth distribution causes a decrease in the growth rate of GDP per capita by $0.31-0.32$ units. Moreover, in this estimation procedure, the variables for the estimation effects of governance factors were introduced. This examination was based on whether or not the relationship between EG and WI is dependent on the level of governance. The governance factors under consideration were accountability and voice, the effectiveness of the government, regulatory quality, corruption control, political stability, the absence of violence, and the rule of law. Results are demonstrated in Table 2 and columns 1-6 show that WI has a recurring and negative influence on the growth factor of the economy. The coefficients of the governance indicators were found to be negative and statistically insignificant. However, the interaction terms generated between WI and the governance indicators were found to be significant for the overall growth output. Therefore, the lone impact of governance factors doesn't nullify or increase the EG of China; however, in the presence of WI, they become important considerations. The results of the first and second order serial correlations analyzed using AR 1 and AR2 tests were insignificant, as were the results of the SARGAN test, which shows that, in both cases, the null hypotheses for the test results were accepted, i.e. the model wasn't overestimated and there was no indication of serial correlation in the results.

\section{Discussion and Conclusion}

Since the financial crisis in 2007-2008, the inequality in the distribution of wealth has been a major issue in developed and economically sound countries (Bogliacino \& Maestri, 2016). The percentages of income and wealth of financially stable populations in emerging countries such as India and China have been found to have increased significantly after the crisis. Studies by Lorenzi (2016) and Islam and McGillivray (2019) evaluated the impact of WI and governance factors in GMM countries and their effects on the EG of the regions under consideration. These studies support the findings of the present study, reporting that an increased WI is detrimental for the economic affluence of the regions under consideration. Kennedy, Smyth, Valadkhani, and Chen (2017) evaluated the effects of income and WI in the Australian context, finding that the negative tax returns for the population were below the average income range; Lee and Son (2016) used a dynamic panel approach, finding the same results as were found in our evaluations. The impact of governance on the economy and its growth factors has been established through the literature (Alam, Kiterage, \& Bizuayehu, 2017; Azam, 2016; Emara, 2016; Franz, 2017; Wilson, 2016). The findings of this study, as well as many other studies, have established the fact that an increase in corruption in developing and developed countries, as well as the poor regulatory environment, have contributed to the increase in income inequality of poverty persistence. This has reduced the EG output of countries and systems, as well as affecting the taxation systems. The association between inequalities in the distribution of wealth and its relationship to EG has become the major focus of many empirical and theoretical investigations. However, the empirical results and justifications are still inconclusive. This study uses data from China to study the impact of WI and governance factors on the EG of the country. The results have been derived from a systematic GMM dynamic panel and the results suggest that the WI has a strong negative impact on the EG of the People's Republic of China. This statistically significant relationship and the resultant adverse impact of WI on EG was found to be present, even when regressors were estimated using the same specifications. The results were found to be robust. Moreover, the economic analysis also included the evaluation of the impact of governance factors on the relationship between EG and WI. The findings suggest that an increased accountability, less corruption, increased and high-quality regulatory institutions, a justifiable rule of law, and a higher stability of the government can help in the eradication and control of WI in order to promote the EG of a region.

\section{Research Implications}

This paper's findings have led to the implementation of several policies and suggestions. The first states that WI is not good for EG, as WI has a strong effect on income and wealth growth factors. Furthermore, institutional reforms would be able to improve the efficiency of governance, and the support of wealth distribution should be focused on reducing the negative impact of WI on EG. Policymakers can improve governance through the mitigation of EG issues brought about by income inequalities and WI in the population. In order to successfully implement governance-focused reforms, a better understanding of the channels that can be used to improve the economic outlook of rapidly developing countries like China is required.

\section{Limitations of the Study}

The primary limitation in this research is the fact that it is geographically constrained to China, as the data has been collected from this country. China is a diverse country that has observed a rapid growth in its economy and is 
gradually emerging as a world power, which differs from other countries in the region. Consequently, the results of the economic and WI factors cannot be generalized across other regions. To improve the effectiveness, reliability, and accuracy of the model, future researchers should include data from other countries and regions.

\section{References}

Adrián Risso, W., \& Sánchez Carrera, E. J. (2019). On the impact of innovation and inequality in economic growth. Economics of Innovation and NewTechnology, 28(1), 64-81. Available at: https://doi.org/10.1080/10438599.2018.1429534.

Akinci, M. (2018). Inequality and economic growth: Trickle-down effect revisited. Development Policy Review, 36, O1-O24. Available at: https://doi.org/10.1111/dpr.12214.

Alam, M. R., Kiterage, E., \& Bizuayehu, B. J. E. B. (2017). Government effectiveness and economic growth. Economic Bulletin, 37(1), $222-227$.

Arellano, M., \& Bover, O. (1995). Another look at the instrumental variable estimation of error-components models. Journal of Econometrics, 68(1), 29-51. Available at: https://doi.org/10.1016/0304-4076(94)01642-d.

Azam, M. (2016). Does governance and foreign capital inflows affect economic development in OIC countries. Journal of Economic Cooperation and Development, $37(4), 21-50$.

Bapuji, H., \& Chrispal, S. (2018). Understanding economic inequality through the lens of caste. Journal of Business Ethics, $162(3)$, 533-551.

Bapuji, H., Ertug, G., \& Shaw, J. D. (2020). Organizations and societal economic inequality: A review and way forward. Academy of Management Annals, 14(1), 60-91. Available at: https://doi.org/10.5465/annals.2018.0029.

Baum, C. F., Schaffer, M. E., \& Stillman, S. (2003). Instrumental variables and GMM: Estimation and testing. The Stata Journal, 3(1), 1-31. Available at: https://doi.org/10.1177/1536867x0300300101.

Berg, A. G., \& Ostry, J. D. (2017). Inequality and unsustainable growth: Two sides of the same coin? IMF Economic Review, 65(4), 792-815. Available at: https://doi.org/10.1057/s41308-017-0030-8.

Bogliacino, F., \& Maestri, V. (2016). Wealth inequality and the great recession. Intereconomics, 51(2), 61-66. Available at: https://doi.org/10.1007/s10272-016-0578-y.

Chen, K.-S., Lee, C.-C., \& Tsai, H. (2019). Taxation of wealthy individuals, inequality governance and corporate social responsibility. Sustainability, 11(7), 1851. Available at: https://doi.org/10.3390/su11071851.

Diao, M. (2018). Does growth follow the rail? The potential impact of high-speed rail on the economic geography of China. Transportation Research Part A: Policy and Practice, 113, 279-290. Available at: https://doi.org/10.1016/j.tra.2018.04.024.

Emara, N. (2016). The impact of governance environment on economic growth: The case of Middle Eastern and North African countries. Journal of Economics Library, 3(1), 24-37.

Franz, T. (2017). Urban governance and economic development in Medellín: An "urban miracle”? Latin American Perspectives, 44(2), 52-70. Available at: https://doi.org/10.1177/0094582x16668313.

Gollin, D. (2002). Getting income shares right. Journal of political Economy, 110(2), 458-474. Available at: https://doi.org/10.1086/338747.

Guan, X., Wei, H., Lu, S., Dai, Q., \& Su, H. (2018). Assessment on the urbanization strategy in China: Achievements, challenges and reflections. Habitat International, 71, 97-109. Available at: https://doi.org/10.1016/j.habitatint.2017.11.009.

Islam, M. R., \& McGillivray, M. (2019). Wealth inequality, governance and economic growth. Economic Modelling, 88, 1-13. Available at: https://doi.org/10.1016/j.econmod.2019.06.017.

Johnson, T., de Dios, E., \& Martin, A. L. (2010). Governance and institutional quality and the links with economic growth and income inequality: With special reference to developing Asia. Asian Development Bank Economics Working Paper Series(193).

Kennedy, T., Smyth, R., Valadkhani, A., \& Chen, G. (2017). Does income inequality hinder economic growth? New evidence using Australian taxation statistics. Economic Modelling, 65, 119-128. Available at: https://doi.org/10.1016/j.econmod.2017.05.012.

Kyriacou, A. P. (2016). Individualism-collectivism, governance and economic development. European Journal of Political Economy, 42, $91-104$. Available at: https://doi.org/10.1016/j.ejpoleco.2015.11.005.

Lee, D. J., \& Son, J. C. (2016). Economic growth and income inequality: Evidence from dynamic panel investigation. Global Economic Reviere, 45(4), 331-358. Available at: https://doi.org/10.1080/1226508x.2016.1181980.

Li, S. (2016). Income inequality and economic growth in China in the last three decades. The Round Table, 105(6), 641-665. Available at: https://doi.org/10.1080/00358533.2016.1246858.

Liu, Y. (2018). Introduction to land use and rural sustainability in China. Land Use Policy, 74, 1-4. Available at: https://doi.org/10.1016/j.landusepol.2018.01.032.

Lorenzi, P. (2016). Inequality and economic growth. Society, 53(5), 474-478.

Ogidan, J., Adekola, O., Grace, E., \& Oluwanishola, O. (2017). ICT for good governance and socio-economic development in Nigeria. World Scientific Nerws, 72, 522-534.

Piketty, T., Yang, L., \& Zucman, G. (2019). Capital accumulation, private property, and rising inequality in China, 1978-2015. American Economic Review, 109(7), 2469-2496. Available at: https://doi.org/10.1257/aer.20170973.

Riti, J. S., Song, D., Shu, Y., \& Kamah, M. (2017). Decoupling $\mathrm{CO} 2$ emission and economic growth in China: Is there consistency in estimation results in analyzing environmental Kuznets curve? Journal of Cleaner Production, 166, 1448-1461. Available at: https://doi.org/10.1016/j.jclepro.2017.08.117.

Ritter, M., \& Solt, F. (2019). Economic inequality and campaign participation. Social Science Quarterly, 10O(3), 678-688.

Roodman, D. (2009). How to do xtabond2: An introduction to difference and system GMM in Stata. The Stata Journal, 9(1), 86-136.

Ruck, M., Mistry, R., \& Flanagan, C. (2019). Children's and adolescents' understanding and experiences of economic inequality: An introduction to the special section. Developmental Psychology, 55(3), 449-456. Available at: https://doi.org/10.1037/devo000694.

Scheffer, M., Van Bavel, B., Van de Leemput, I. A., \& Van Nes, E. H. (2017). Inequality in nature and society. Proceedings of the National Academy of Sciences, 114.(50), 13154-13157.

Scheve, K., \& Stasavage, D. (2017). Wealth inequality and democracy. Annual Review of Political Science, 20, 451-468.

Shi, X., \& Sun, S. (2017). Energy price, regulatory price distortion and economic growth: A case study of China. Energy Economics, 63(C), $261-$ 271. Available at: https://doi.org/10.1016/j.eneco.2017.02.006.

Stiglitz, J. E. (2016). Inequality and economic growth.

Suisse, C. (2013). Global wealth report 2013. Zurich: Crédit Suisse.

Wei, S.-J., Wu, W., \& Zhang, L. (2019). Portfolio choices, asset returns and wealth inequality: Evidence from China. Emerging Markets Review, 38(C), 423-437. Available at: https://doi.org/10.1016/j.ememar.2018.11.011.

Wilson, R. (2016). Does governance cause growth? Evidence from China. World Development, 79(C), 138-151. Available at: https://doi.org/10.1016/j.worlddev.2015.11.015.

Wu, X., \& Li, J. (2017). Income inequality, economic growth, and subjective well-being: Evidence from China. Research in Social Stratification and Mobility, 52, 49-58. Available at: https://doi.org/10.1016/j.rssm.2017.10.003.

Zhao, J., \& Tang, J. (2018). Industrial structure change and economic growth: A China-Russia comparison. China Economic Review, 47(C), 219-233. Available at: https://doi.org/10.1016/j.chieco.2017.08.008.

Zhou, Y., \& Song, L. (2016). Income inequality in China: Causes and policy responses. China Economic Journal, 9(2), 186-208. Available at: https://doi.org/10.1080/17538963.2016.1168203. 